\title{
Therapeutic cardiac angiogenesis and myogenesis: The promises and challenges on a new frontier
}

Ray C.-J. Chiu, MD, PhD

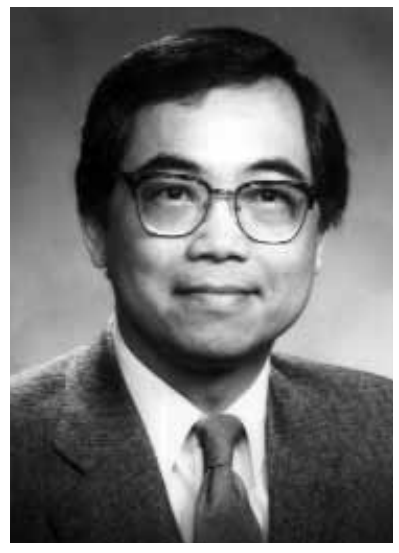

See related article on page 963 .

From McGill University, Montreal, Quebec, Canada.

Received for publication June 8, 2001; accepted for publication June 27, 2001.

Address for reprints: Ray Chu-Jeng Chiu, $\mathrm{MD}, \mathrm{PhD}$, Department of Surgery, Montreal General Hospital, McGill University, 1650 Cedar Ave, C9-169, Montreal, PQ H3G 1A4, Canada.

J Thorac Cardiovasc Surg 2001;122:851-2

Copyright (C) 2001 by The American Association for Thoracic Surgery

$0022-5223 / 2001 \$ 35.00+0 \quad \mathbf{1 2 / 1 / 1 1 8 4 9 9}$

doi:10.1067/mtc.2001.118499

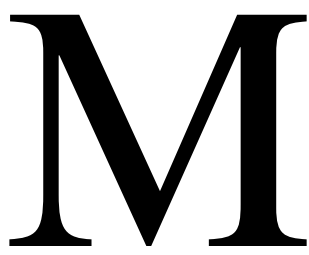

yocardial circulatory insufficiency, cardiomyocyte necrosis, and apoptosis play important roles in many pathologic conditions of the heart. Therapeutic approaches aimed at promoting angiogenesis and growing new heart muscle fibers, currently undergoing intensive investigation and early clinical trials, therefore hold considerable promise for the future. Genes encoding angiogenic factors and angiogenic growth factor proteins, such as vascular endothelial growth factor (VEGF) and basic fibroblast growth factor, are being delivered to the target tissue to induce growth of new blood vessels. For myogenesis, various progenitor and stem cells are being assessed as donor cells for implantation into the ventricular wall of injured hearts. Phase I and II clinical trials have already been undertaken for myocardial angiogenesis. Clinical studies into myogenesis have been recently initiated with implantation of autologous skeletal myoblasts into myocardial scar tissue. Although the results of phase I safety studies so far are promising, the establishment of efficacy requires rigorous phase II and III studies yet to come.

Cardiac myogenesis and angiogenesis represents a paradigm shift in our therapeutic approach, from substitution to regeneration of irreversibly damaged cardiac tissues and structures. These new modalities of therapy will not be constrained by the scarcity of donor organs, immunologic rejection, or the need for mechanical devices requiring maintenance and replacement. Regenerative medicine and surgery are in fact in vivo "tissue engineering." This could be supplemented by in vitro tissue engineering in which an anatomic structure such as a heart valve could be fabricated with the use of a patient's own cells, culturing and growing them in vitro on appropriate biodegradable scaffolds. Such regenerated tissues and constructs may not only function normally, but also should be able to grow and remodel.

Yet in the short term this new frontier contains many challenges. Optimal means of inducing angiogenesis remain elusive, and many questions persist. For example, the strategy of using genetically engineered cells to deliver angiogenic genes to the target tissue has been pursued by many investigators. However, would endothelial cell transplantation per se be useful for angiogenesis, as suggested in an accompanying article by Kim and associates? ${ }^{1}$ In the presence of appropriate angiogenic factors, at present there is no evidence of a shortage of endothelial cells for angiogenesis. These can be derived from local vascular budding (angiogenesis), as well as from circulating pro-endothelial cells (vasculogenesis), which, as recent evidence shows, could be recruited from the bone marrow. ${ }^{2}$ In vitro, endothelial cells in culture will form tubular capillary structures only in the presence of angiogenic growth factors. In vivo, reduction in angiogenic factor stimulus during scar remodeling results in the regression of vascularity with apoptosis of endothelial cells. Thus, the observation of Kim and colleageus ${ }^{1}$ that angiogenesis was induced with endothelial cell transplantation into a scar without increased VEGF expression is provocative. Perhaps such a finding could be further confirmed in a future study, if angiogenesis can indeed be induced by endothelial transplantation despite blockage of VEGF or VEGF receptors.

However, an increase in capillary density does not necessarily lead to better blood perfusion, unless the capillaries mature and connect with arterial inflow. 
Many of the capillaries in the body are not open under basal conditions. The magnitude of tissue perfusion is controlled by the arteriolar tone, and capillaries are recruited to carry blood flow to meet tissue demands. Thus, increase in blood flow may not necessarily follow increased capillary density by angiogenesis, and coronary blood flow measured ex vivo may not represent actual blood flow in vivo.

Likewise, in the myoblast implant studies, a number of perplexing questions also remain. The skeletal myoblasts transplanted into the ventricular wall of a heart have been reported to differentiate either into skeletal slow-twitch muscle fibers ${ }^{3}$ or transdifferentiate into cardiomyocytes. ${ }^{4}$ In one study, it was reported that these myoblasts may express two different phenotypes, with skeletal muscle phenotype in the center of a myocardial scar and features of immature cardiomyocytes at the ischemic border zone. ${ }^{5}$ Furthermore, such myoblasts implanted into myocardial scar have been reported to improve systolic fiber shortening, even though no syncytial integration of these cells with native myocardial fibers could be recognized because they were surrounded by the fibrous scar tissue. ${ }^{6}$ This is curious inasmuch as an anatomic supracellular integration seems a necessary prerequisite for synchronized contractions of these new muscle cells during ventricular systole. Clarifying such dilemmas should help us in accepting some of the findings being reported from functional studies.

Recently, cells other than the myoblasts, such as the adult stem cells in the bone marrow, are being studied as donor cells for cellular cardiomyoplasty, as they are more versatile stem cells capable of differentiating into many phenotypes, including cardiomyocytes, endothelial cells, and myofibroblasts. ${ }^{7}$ Attempts are also being made to transfect myoblasts and stem cells with angiogenic genes during culture before their implantation into the myocardium, in an effort to achieve both cardiac angiogenesis and myogenesis simultaneously. There is, however, some evidence that these cells may spontaneously express angiogenic factors in vivo and induce angiogenesis while they differentiate, so that whether in fact preimplant genetic engineering is required remain to be further examined.

Central to future advancement in this new frontier is to learn how signals are presented physically and temporally to cells and how cells integrate multiple signals to generate a response. With such understanding, we will learn how to manipulate the microenvironment, both in vitro and in vivo, so that we can better design tissues and constructs to meet our therapeutic needs.

\section{References}

1. Kim E-J, Li R-K, Weisel RD, Mickle DAG, Jia Z-Q, Tomita S, Sakai T, Yau TM. Angiogenesis by endothelial cell transplantation. J Thorac Cardiovasc Surg. 2001;122:963-7.

2. Takahashi T, Kolka C, Masuda H, Chen D, Silver M, Kearney M, et al. Ischemia and cytokine induced mobilization of bone marrow derived endothelial progenitor cells for neovascularization. Nature Med. 1999; 5:434-8.

3. Murry CE, Wiseman RW, Schwartz SM, Hauschka SD. Skeletal myoblasts transplantation for repair of myocardial necrosis. $J$ Clin Invest. 1996;98:2512-23.

4. Kao RL, Chin TK, Ganote CE, et al. Satellite cell transplantation to repair injured myocardium. Card Vasc Regen. 2000;1:31-42.

5. Atkins BZ, Lewis CW, Kraus WE, Hutcheson KA, Glower DD, Taylor DA. Intracardiac transplantation of immature skeletal myoblasts yields two population of striated cells in situ. Ann Thorac Surg. 1999;67:124-9.

6. Taylor DA, Atkins BZ, Hungspreugs P, Jones TR, Reedy MC, Hutcheson KA, et al. Regenerating functional myocardium: improved performance after skeletal myoblast transplantation. Nat Med. 1998; 4:929-33.

7. Wang J-S, Shum-Tim D, Chedrawy E, Chiu RC-J. The coronary delivery of marrow stromal cells for myocardial regeneration: pathophysiologic and therapeutic implications. J Thorac Cardiovasc Surg. 2001; 122:699-705. 